Journal of Materials and Environmental Sciences ISSN : 2028-2508

CODEN : JMESCN

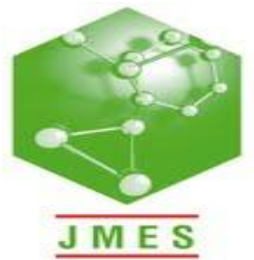

\title{
Simulation Methods for Joining of Tools with Complex Geometries by Brazing
}

\author{
D. Bartout ${ }^{1}$, N. Süleymanov ${ }^{2}$ \\ 1. Department of Industrial Maintenance, ESTS, Mohammed V University of Rabat, Morocco \\ 2. Institute of Joining and Coating Technology, Technical University of Berlin, Germany
}

Received 13 Feb 2017, Revised 07 Aug 2017 , Accepted 14 Aug 2017

Keywords

$\checkmark$ Steel X20Cr13;

$\checkmark$ High Temperature Brazing;

$\checkmark$ Residual Stress;

$\checkmark$ Austenite-Martensite;

$\checkmark$ FE-Simulation

D. Bartout driss.bartout@tu-berlin.de $+212621348473$

\section{Abstract}

This study presents a finite element modeling (FE) of the temperature field and residual stress during high temperature brazing process of tool components with cooling channels and asymmetric geometry. The thermo-mechanical analysis was developed by using the commercial software Ansys 12 [1]. The thermal and mechanical material properties are introduced as temperature dependent functions, due to the material phase changes (austenite-martensite) occurring in the steel $\mathrm{X} 20 \mathrm{Cr} 13$ during brazing. The results indicate that the model can effectively predict the stress and the temperature distribution during the brazing process. The experimental results can be implemented in a FEsimulation in order to provide recommendations for the optimization of the process and the control of residual stresses in the joint.

\section{Introduction}

Production technologies enable the fabrication of machining tools with complex geometries and high accuracy. Tools with cooling channels for example are manufactured in individual parts and later joined by high temperature brazing. During brazing of components with cooling channels and different material properties, temperature gradients can emerge leading to high residual stresses. The appearance of residual stress in and around the cooling channels can be detrimental to the durability of the tool. In this work a FE-model for CDpress matrices has been developed. This is an injection molding insert which consists of two individual parts and is based on an injection molding tool for the production of CD blanks. This demonstrator geometry was jointly defined by the members of the project accompanying committee. The simulation enables analyzing the thermal stress, predicting the temperature distribution during the brazing process [2, 3] and providing information about the effect of phase changes on the stress development in the base material $[4,5,6]$.

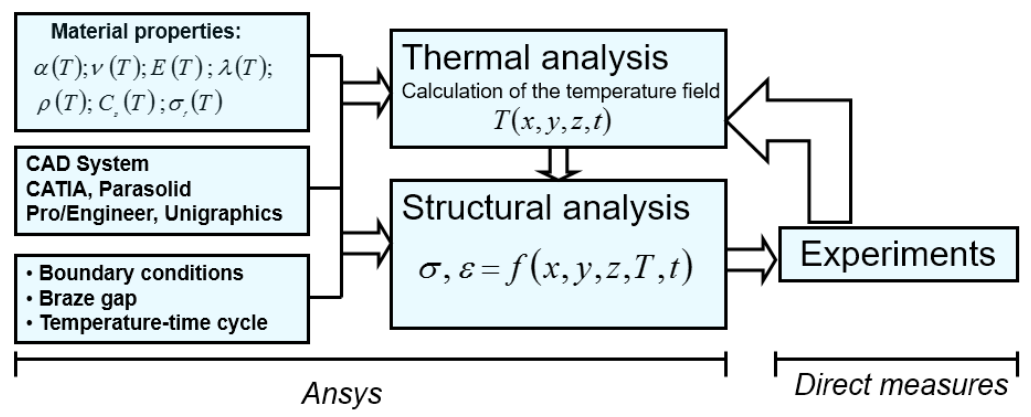

Figure 1: Approach of modelling of the brazing process measurements 


\section{Modelling Procedure}

\subsection{Analysis strategy}

The thermal residual stress simulation is performed sequentially in two steps. First, the temperature distribution of the brazed components is computed and then employed as a thermal load in the subsequent calculation of residual stress field. The component is warmed up to the brazing temperature between $1000-1050{ }^{\circ} \mathrm{C}[7,8]$. The heat transfer is assumed to occur by external thermal radiation and thermal conduction inside the components. Thermal analysis suggests that the convection and radiation contributions during heating are very low in comparison with the thermal conduction during the brazing process. The thermal computations are based on the nonlinear heat transfer equation which was developed to handle transient three-dimensional finite element solutions $[9,10,11]$.

$$
\left(\lambda_{x} \frac{\partial^{2} T}{\partial x^{2}}+\lambda_{y} \frac{\partial^{2} T}{\partial y^{2}}+\lambda_{z} \frac{\partial^{2} T}{\partial z^{2}}\right)+\rho c_{p} \frac{\partial T}{\partial t}=\bar{f}
$$

For equation (1.1), nonlinear boundary conditions of the following kinds were used [12]:

- Prescribed heat flux or Neumann boundary condition

$$
q=\bar{q} \text { where } q=\lambda(T) \frac{\partial T}{\partial n} q=\bar{q}
$$

- Convective boundary condition

$$
q=-\alpha\left(T-T_{e n v}\right)
$$

- The nonlinear convective boundary condition can be written as

$$
\begin{gathered}
\lambda(T) \frac{\partial T}{\partial n}=-\alpha\left(T-T_{e n v}\right) \\
\frac{\partial T}{\partial n}+\frac{\alpha}{\partial(T)} T=\frac{\alpha}{\partial(T)} T_{e n v}
\end{gathered}
$$

- Radiation boundary condition

$$
q=\sigma \varepsilon\left(T^{4}-T_{r}^{4}\right)
$$

\begin{tabular}{|l|l|}
\hline $\mathrm{q}$ & Heat flux density \\
\hline$\lambda(\mathrm{T})$ & Thermal conductivity of the medium \\
\hline $\mathrm{n}$ & The normal \\
\hline$\alpha$ & Convective heat coefficient \\
\hline$T_{e n v}$ & Temperature of the medium \\
\hline$\sigma$ & Stefan-Boltzmann constant \\
\hline$\varepsilon$ & Emissivity between the surface and the boundary at temperature $T_{r}$ \\
\hline$T_{r}$ & Room temperature \\
\hline
\end{tabular}

Temperature dependent material properties have been implemented into the model for the selected materials. Thermo-mechanical data included: density, specific heat, thermal conductivity, thermal expansion coefficient, Young's modulus and Poisson's ratio. The material model considered is a kinematic hardening model proposed by von Mises and Hill is shown in Figure 2. The constitutive equations are based on the von Mises yield function and the associated flow rule. The model can be used to simulate the Bauschinger effect, the complicated plastic behaviour of materials such as hardening [13]. 


\subsection{Model formulation}

A 3D-CAD-model of the components used in the study is presented in Figure 2.
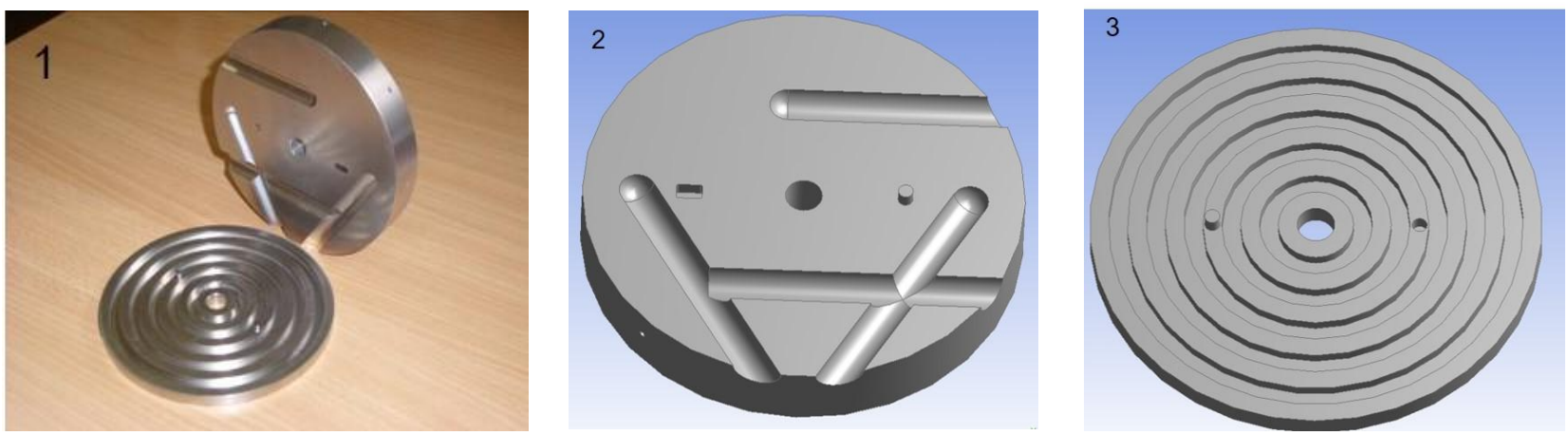

Figure 2: Particle size distribution of silver nanoparticles from dynamic light scattering measurements

Main geometrical features are:

$>$ thickness of elements $6 \mathrm{~mm}, 20 \mathrm{~mm}$

$>$ brazing gap $0.05 \mathrm{~mm}$

$>$ diameter of $120 \mathrm{~mm}$

The tetrahedral mesh is generated automatically (Fig. 3). The high stress regions and the contact regions were locally refined. This is important in order to reduce the computational time required for the calculation and to obtain a more detailed solution close to the considered regions.

X20Cr13 and X5CrNi18-10 steels are used as base materials and Nickel based L -Ni 2 as a brazing foil. The material properties were inserted and defined in the pre-processing step of Ansys [1]. For more realistic predictions concerning residual stresses in the components, it is essential to consider the complex effects of phase transformation in the simulation. The formation of martensite is based on the Koistinen-Marburgerequation for diffusionless transformation $[14,15,16]$ :

$$
y^{\text {mar }}=y^{\text {aus }}\left(1-\exp \left(\alpha\left(\mathrm{M}_{x}-T\right)\right)\right)
$$
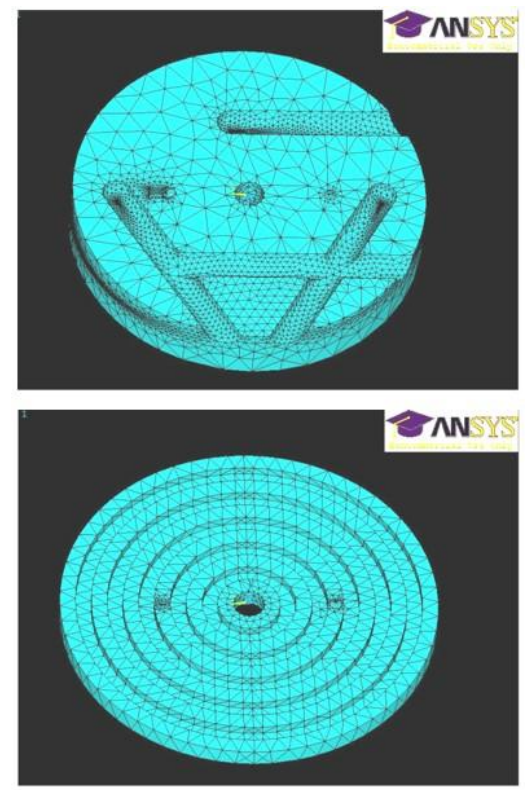

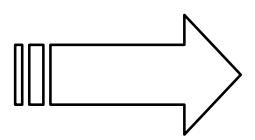

A refine area
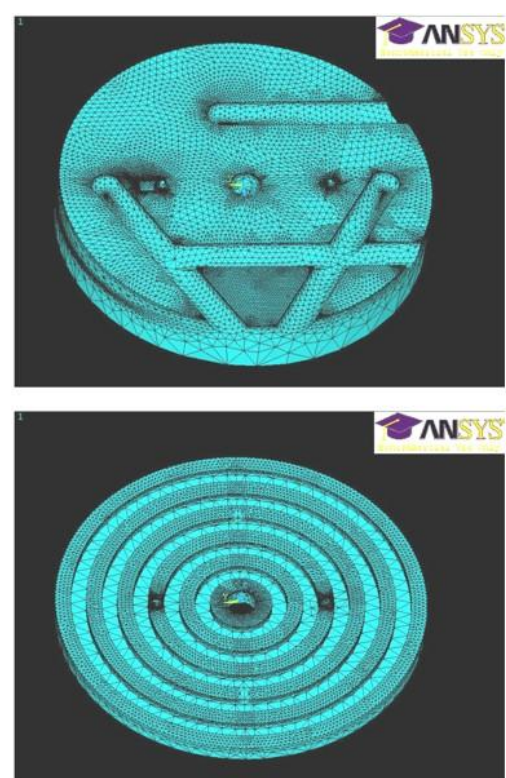

Figure 3: Mesh generation 
In the cooling phase and in the case of higher cooling rates, the yield strength increases in the temperature range between $473 \mathrm{~K}$ and $373 \mathrm{~K}$ by the increasing martensite fraction in the structure. The volume change in the base material as a result of thermal expansion as well as the phase transformation have a great influence on the stress formation in the brazed joint. During the calculation, temperature-dependent thermal expansion coefficients for each phase were implemented in the model to account for the volume leap during the phase transformation of the steel (X20Cr13). Figure 4 shows dilatometer curves of steel X20Cr13 during heating and cooling cycles [17]. The thermal expansion has increased with increasing temperature. At TMs $=573 \mathrm{~K}$ (cooling rate $=0.14 \mathrm{~K}$ / s), the austenite phase changes into the martensite phase. This transformation was accompanied by a volume change which can lead to stresses.
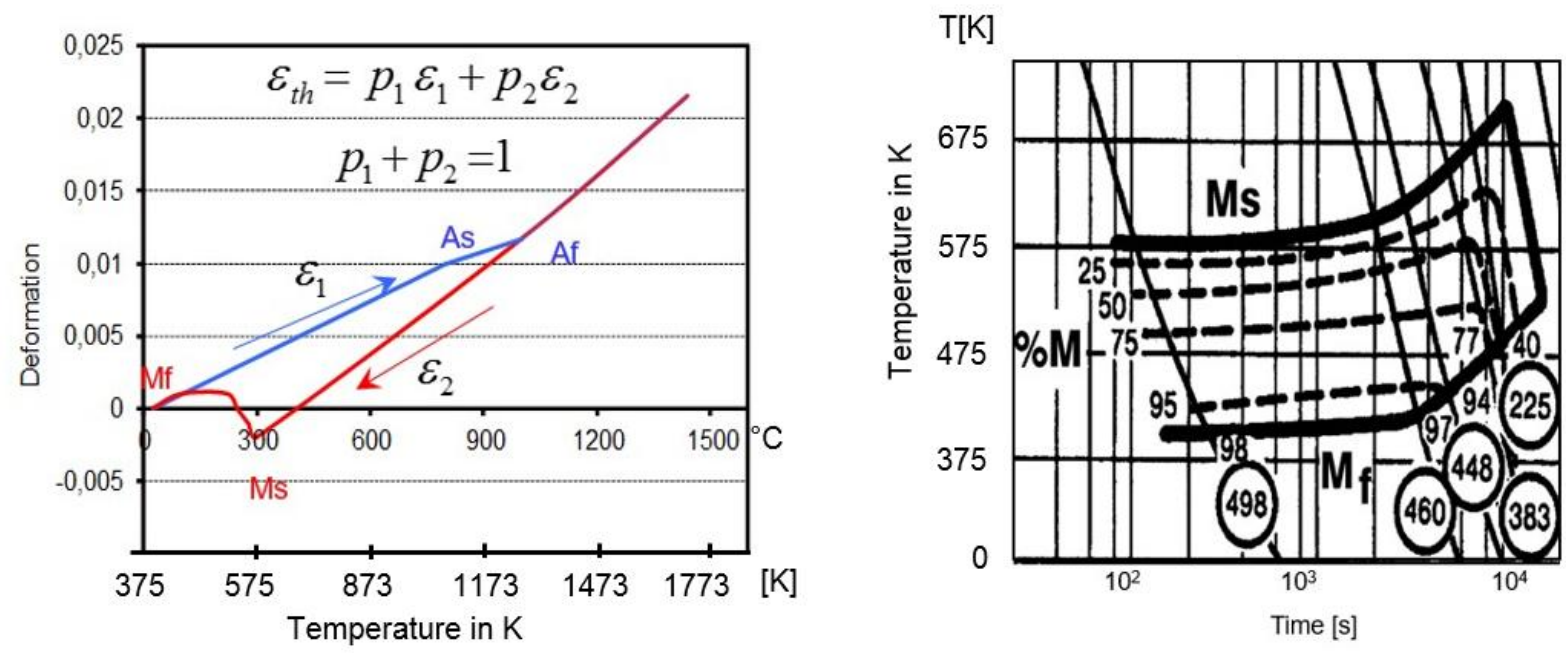

Figure 4: Dilatometer curves for steel X20Cr 13

\section{Results and Discussion}

\subsection{Temperature field}

The brazing cycle used for simulation is presented in Figure 5. The temperature profile consists of three stages. First the component is gradually heated to the brazing temperature $(1273,15-1323,15 \mathrm{~K})$ at the speed of 10 $\mathrm{K} / \mathrm{min}$, then held at $1323,15 \mathrm{~K}$ for $30 \mathrm{~min}$ and finally cooled down from brazing to room temperature at 35 $\mathrm{K} / \mathrm{min}$ for the first and $100 \mathrm{~K} / \mathrm{min}$ for the second brazing cycle.

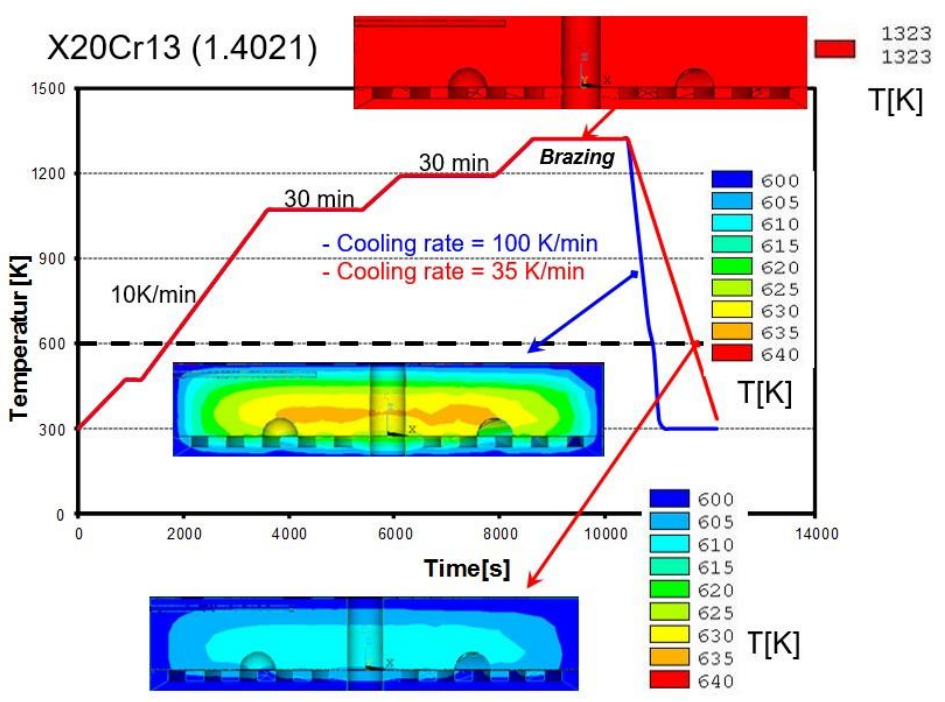

Figure 5: Temperature profile in the component 
Figure 6 shows the temperature distribution in the upper component. During brazing of the components with complex geometries, temperature gradients can be observed. The result of the numerical calculation documents that the high cooling rate $(100 \mathrm{~K} / \mathrm{min})$ causes higher temperature gradients in the base material (X20Cr13). The temperature difference between the centre and the outer surface of the component is $10 \mathrm{~K}$ at the cooling rate of $35 \mathrm{~K} / \mathrm{min}$ and $35 \mathrm{~K}$ at $100 \mathrm{~K} / \mathrm{min}$. The difference of temperature inside and outside the component causes great distortion which has a negative impact on the life cycle of the tool.

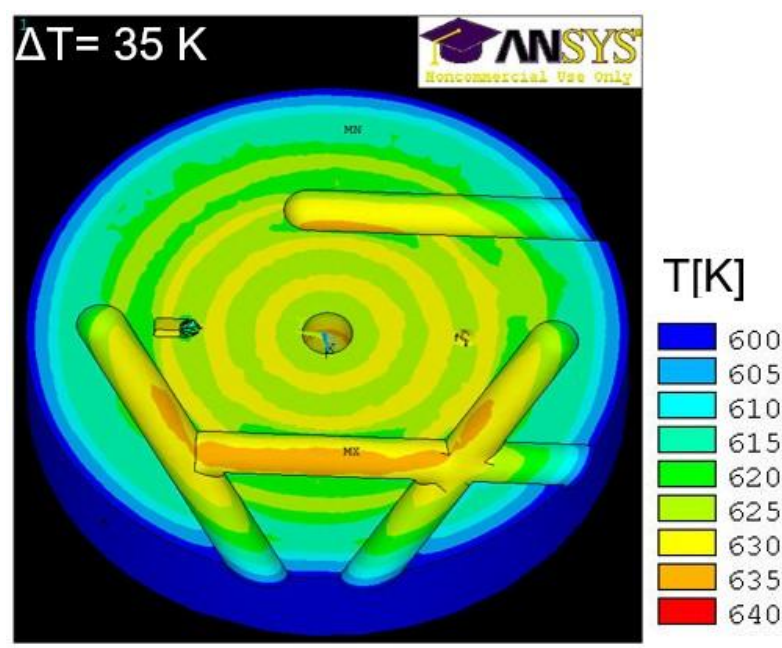

Cooling rate $=100 \mathrm{~K} / \mathrm{min}$

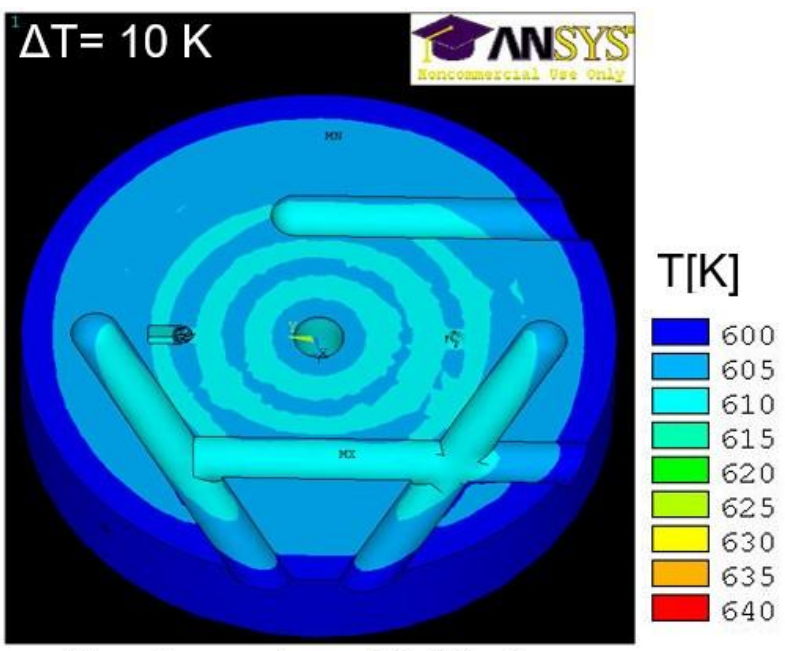

Cooling rate $=35 \mathrm{~K} / \mathrm{min}$

Figure 6: Temperature distribution in the upper components

Figure7 shows the temperature distribution in the lower component (X20 $\mathrm{Cr} 13)$. The difference of the temperature attains the value of $5 \mathrm{~K}$ at a cooling rate of $35 \mathrm{~K} / \mathrm{min}$ and $25 \mathrm{~K}$ at $100 \mathrm{~K} / \mathrm{min}$.

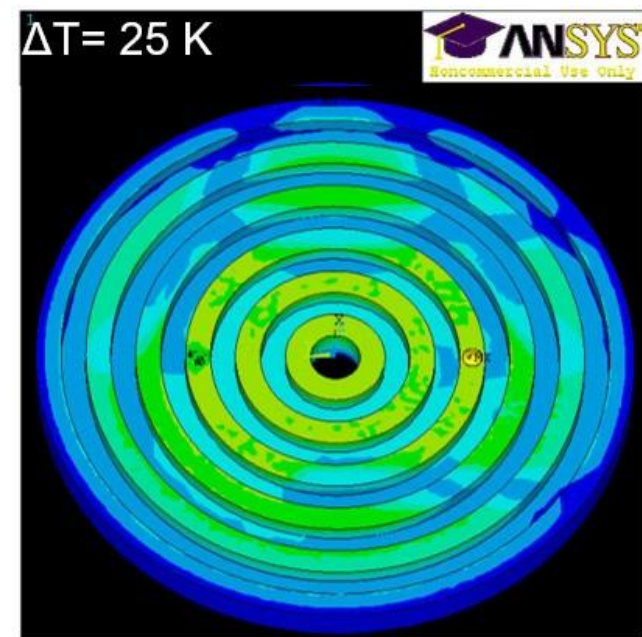

Cooling rate $=100 \mathrm{~K} / \mathrm{min}$

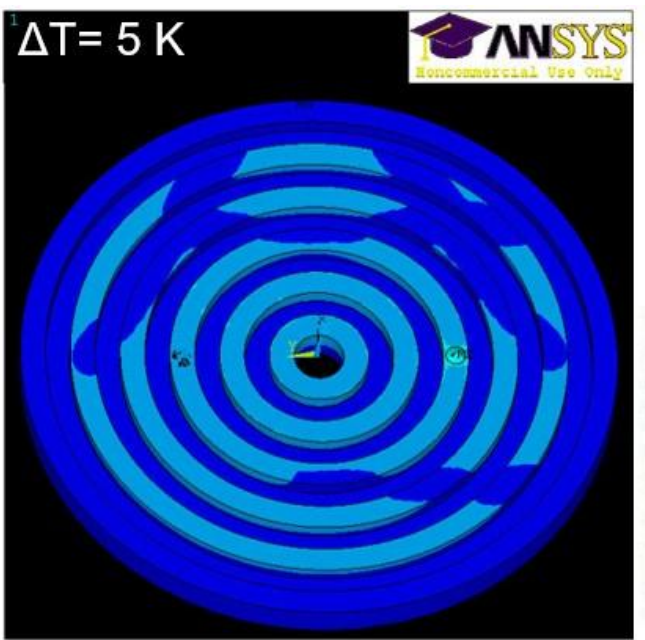

Cooling rate $=35 \mathrm{~K} / \mathrm{min}$
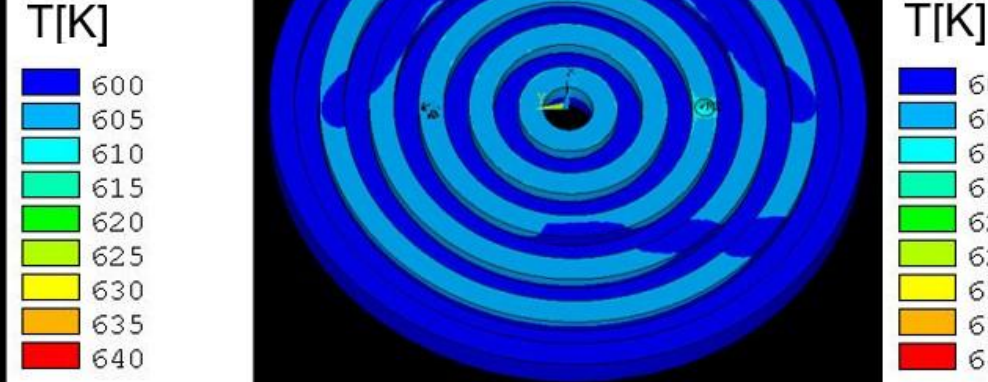

Figure 7: Temperature distribution in the lower components

It is concluded that the cooling rate has a significant effect on the temperature gradient and therefore on the stress concentration in the components.

\subsection{Residual stress}

The stress distribution analysis shows that during heating low values emerge. During cooling high stresses appear in the base material. The reason is that the material properties of the base metal and the filler metal are dissimilar. The different thermal coefficients result in permanent deformation. High temperature gradients have great effect on the stress distribution and consequently on the residual stresses [18]. 
Figure 8 presents the distribution of the stress components. The maximum values of longitudinal stress $\sigma_{\mathrm{xx}}$ and transversal stress $\sigma_{y y}$ during cooling at $100 \mathrm{~K} / \mathrm{min}$ are $85 \mathrm{MPa}$ and $70 \mathrm{MPa}$, respectively. In addition, the simulation results have shown the effect of the material phase change on the stress distribution in the base material (X20Cr13). The austenite-martensite transformation causes stress degradation in the base material and at the end of the brazing cycle, a persistent residual stress of $57 \mathrm{MPa}$ in the $\mathrm{x}$-ax.is direction and $72 \mathrm{MPa}$ in the $\mathrm{y}$-axis direction $[19,20]$.
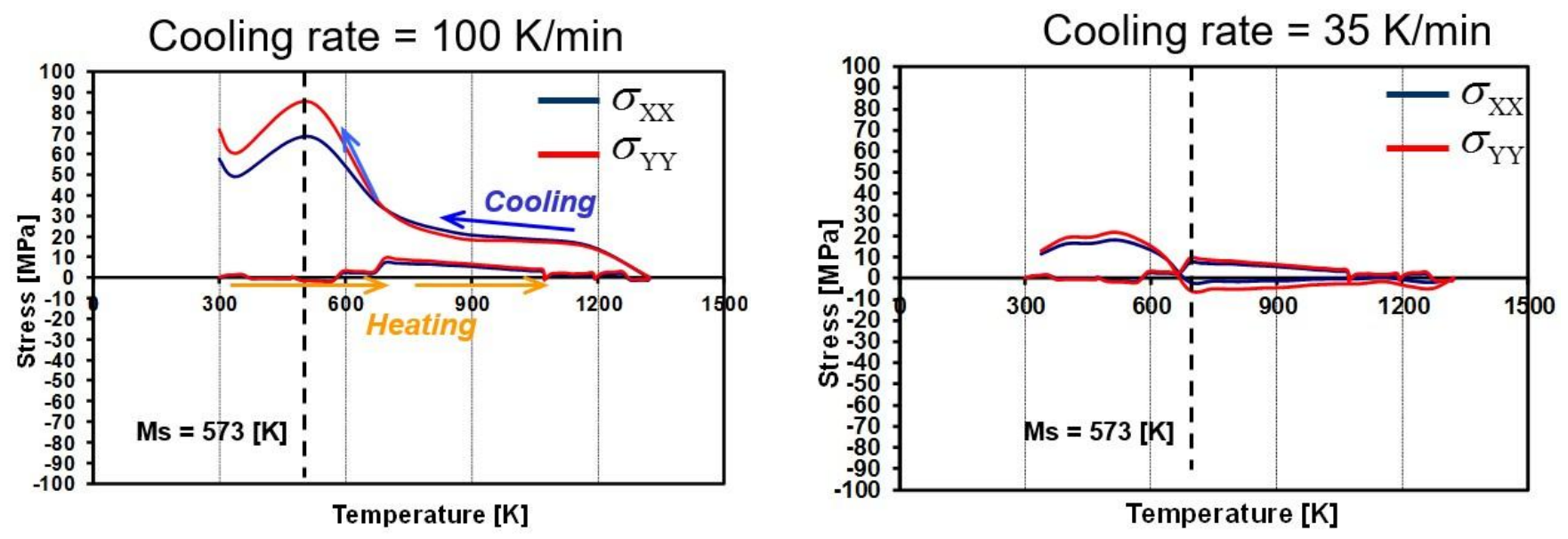

Figure 8: Stress distribution in the base material (X20CrJ3)

\subsection{Experimental validation}

Temperature profiles are measured at different positions (BI, B2, B3, B4, B5) (Fig. 9). It is shown that during the brazing cycle, temperature difference emerges in the component. The measured temperature difference between the positions B5 and B4 for example attaints $60 \mathrm{~K}$ during the heating cycle, and $103 \mathrm{~K}$ during cooling. The experimental results indicate that the heat transfer in components with complex geometries is inhomogeneous. The components are also subjected to a very extreme deformation, especially during the cooling cycle. The measured temperature data are compared with computed results.

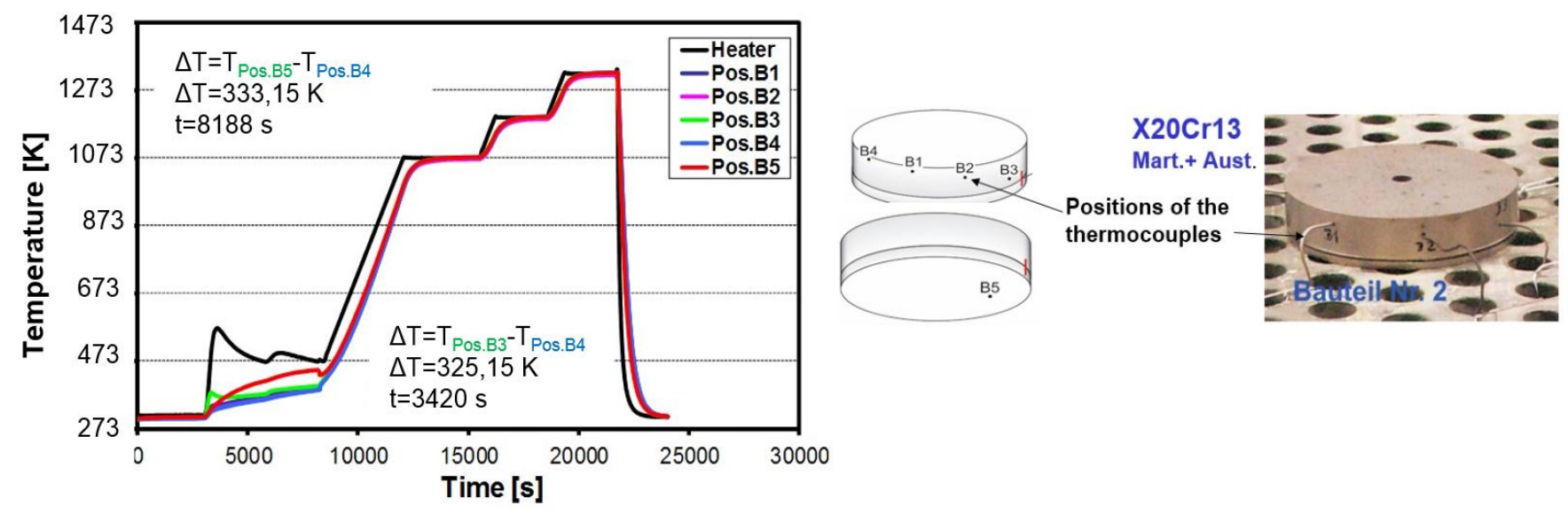

Figure 9: Stress Temperature measured in the component (CrNi-Steel)

Figure 10 illustrates the simulated and the measured temperature profile in B3: the comparison shows that numerical results of temperature match with the experimental data.

In the evaluations, a maximum temperature difference of $20 \mathrm{~K}$ between the simulation and the experiment at the position B3 was determined during the cooling phase.

The thermal stress distribution in components with tempered channels is shown in Figure 11. It can be seen that the highest thermal stresses are located in the middle part of the component. Moreover, stress peaks intensity of $100 \mathrm{MPa}$ emerges in the cooling channels. 


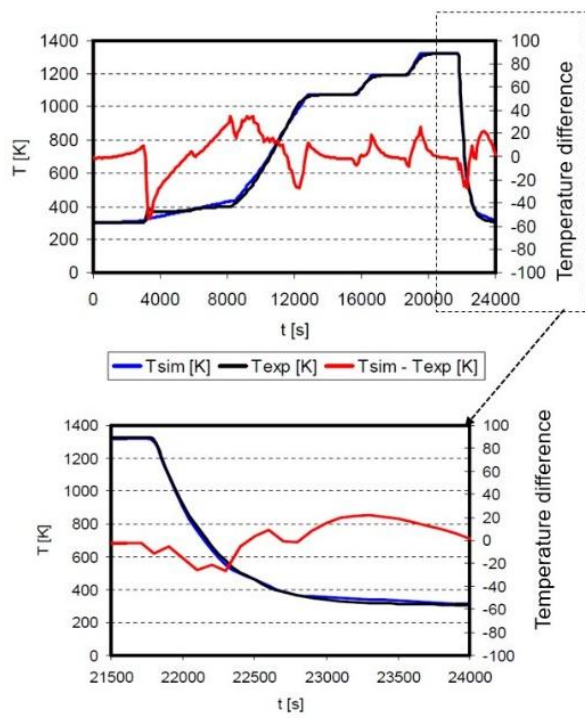

Figure 10: Temperature measured in the component

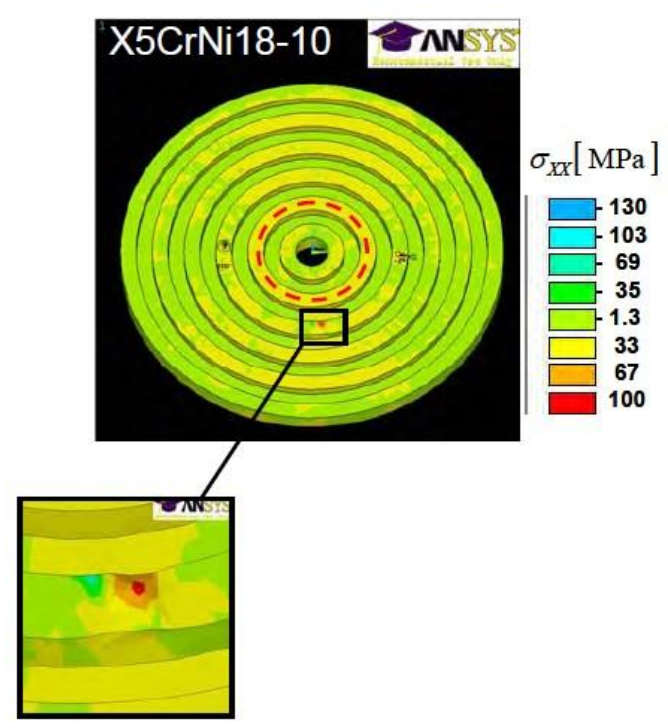

Figure 11: Stress distribution in the component with tempered channels

Calculations with a change in the geometry or shape of the cooling channels in the lower part showed decreasing amounts of the maximum residual stresses in the base material. A rounding off of the sharp edges of the cooling channels with a radius $r=0.5 \mathrm{~mm}$ resulted in a higher decrease of the tensile stresses. At a cooling rate of $100 \mathrm{~K} / \mathrm{min}$, tensile stresses of $7.6 \mathrm{MPa}$ emerged, and the stress distribution was inhomogeneous, what could lead to a local stress concentration and finally to failure. Figure 12 shows that the rounding off of the sharp edges has caused a reduction in the tensile stresses. It is also clear that homogeneous compressive stresses have formed in the component.

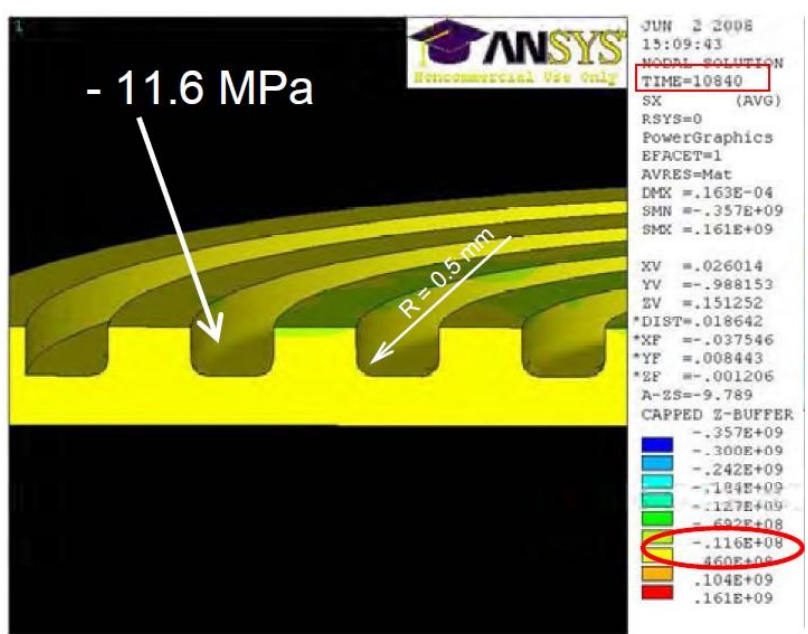

Abkühlrate $=100 \mathrm{~K} / \mathrm{min}$

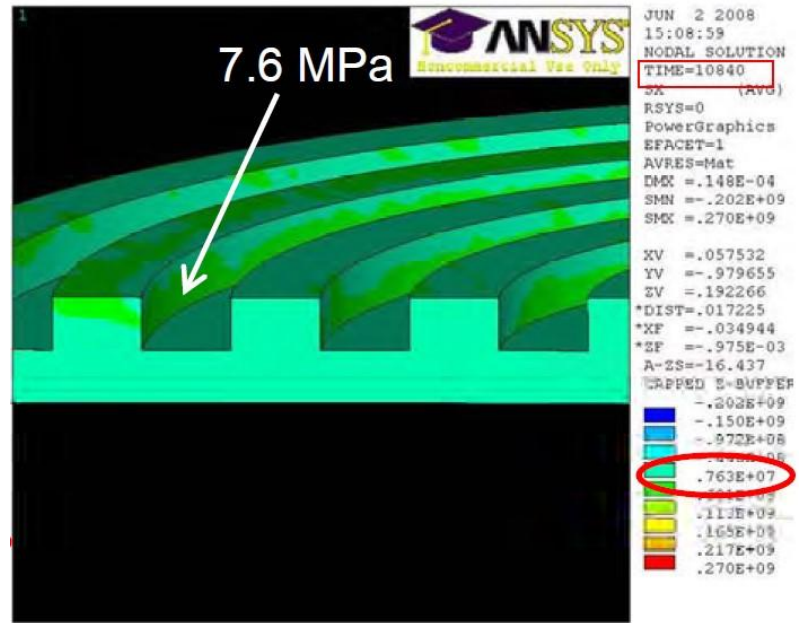

Abkühlrate $=100 \mathrm{~K} / \mathrm{min}$

Figure 12: Influence of the geometry adjustment

\section{Conclusion}

The presented results provide an insight into the residual stresses occurring in the base and the brazing material of the tool components with cooling channels and asymmetric geometry during brazing. In addition, experimental investigations were carried out on the temperature profiles in the component for the validation of the developed model and for demonstration. The investigations prove that the heating respectively the cooling of the component is inhomogeneous during the brazing process. This is a confirmation of the calculations which showed that with increasing cooling rate higher temperature gradients emerge in the component. The edge area cooled faster than the core area. The temperature differences were up to $35 \mathrm{~K}$. This can cause considerable distortions and stresses in the solder connection, which limit the lifecycle of the tool. 
Apart from the adaptation of the brazing cycle, the geometry also has an influence on the emergence of thermal stresses. Therefore calculations on the basis of geometry adjustments were implemented. These show that with minor adjustments, the stresses within the component may be affected. Thus, the sharp transitions of the cooling channels in the lower part were rounded. This approach resulted in a decrease of stress peaks. The FE-model was used to predict the thermal behaviour in the component and to control the temperature uniformity during the brazing cycle by modifying the programmed brazing cycle.

\section{References}

1. ANSYS, Inc., ANSYS FLUENT 12.0, User's Guide, (2009)

2. Wenchun J., Jianming G., ShandongT., Hu C., Modelling of temperature field and residual stress of vacuum brazing for stainless steel plate-fin structure, J. Mat. Pro. Tech. 209 (2009) 1105-1110.

3. Wenchun J., Jianming G., ShandongT., Qinshan F., A comparison of brazed residual stress in plate-fin structure made of different stainless steel, Mater Des. 30 (2009) 23-27.

4. Hartmann T., Proceedings of the 11th International Conference of Brazing, High Temperature Brazing and Diffusion Bonding ( 2016) 239.

5. Bartout D., AiF-Projekt: 14.814 BR DVS Nr. 07.03.2-2 (2009) 7.

6. Qinguo Z., Sicheng Q., Runda M., Case Studies in Thermal Engineering 8 (2016) 32.

7. Wielage B., Martinez L., DVS Berichte 212 (2001) 346.

8. Müller W., Metallische Lotwerkstoffe, Deutscher Verlag für Grundstoffindustrie (1990) 94.

9. Knothe K., Wessels H., Finite Elemente: eine Einführung für Ingenieure, Springer-Verlag Berlin Heidelberg (1999) 70-74.

10. Radaj D., Wärmewirkungen des Schweißens Temperaturfeld, Eigenspannungen, Verzug, SpringerVerlag (1988) 19-21.

11. Huiping L., Guoqun Z., Lianfang H., Yue M., Appl. Math. Model. 33 (2009) 329.

12. Buckley, Donovan O., FIU Electronic Theses and Dissertations, (2010) 3.

13. Guokai Z., Chuan S.W., Xinfeng L., J. Mat. Pro. Tech. 215 (2015) 7.

14. Eigenmann B., Konferenz Einzelbericht, Gefüge und Bruch Bochum (1999) 60.

15. Hippchena P., Lippa A., Grassa H., Craigheroa P., Fleischera M., Merkleinb M., J. Mat. Pro. Tech. 228 (2016) 59.

16. Paul H., Arnulf L., Hannes G., Philipp C., Michael F., Marion M., J. Mat. Pro. Tech. 228 (2016) 59.

17. ESI GROUP (2008) Thewelding simulation solution, February

18. Tremla R., Kozicb D., Zechnerc J., Maederc X., Sartoryb B., Gänserb H.P., Schöngrundnerb R., Michlerc J., Brunnerb R., Kienera D., Acta Mater. 103 (2016) 616.

19. Virginia G.N., Josu L., Jon L., Carmen S., Metall. Mater. Trans. A 46 (2015) 3140.

20. Suxin Q., Yunlong G., Yi W., Jiazhen L., Yunho H., Reinhard R., Ichiro T., Jun C., Materials, cycles and system integrations, Int. J. Refrig. 64 (2016) 1.

\section{(2017) ; http://www.jmaterenvironsci.com}

